\title{
Influence of Intermediate Principal Stress on Undrained Behavior of Intact Clay under Pure Principal Stress Rotation
}

\author{
Jian Zhou, ${ }^{1,2}$ Jiajia Yan, ${ }^{1,2}$ Changjie $X u^{1,2}$ and Xiaonan Gong ${ }^{1,2}$ \\ ${ }^{1}$ Research Center of Coastal and Urban Geotechnical Engineering of Zhejiang University, Hangzhou 310058, China \\ ${ }^{2}$ Institution of Geotechnical Engineering of Zhejiang University, Hangzhou 310058, China \\ Correspondence should be addressed to Jiajia Yan; yanjia.01@163.com
}

Received 10 July 2013; Revised 25 September 2013; Accepted 6 October 2013

Academic Editor: Xu Zhang

Copyright (c) 2013 Jian Zhou et al. This is an open access article distributed under the Creative Commons Attribution License, which permits unrestricted use, distribution, and reproduction in any medium, provided the original work is properly cited.

\begin{abstract}
This study presents the accumulations of the excess pore water pressure and the deformation as well as the noncoaxial behavior of intact soft clay subjected to pure principal stress rotation. Series of tests were carried out by using a dynamic hollow cylinder apparatus to highlight the influence of intermediate principal stress parameter $b$. It was found that the rate of PWP evolution was greatly influenced by $b$, but the influence was not monotonous. Specimens under the condition $b=0.75$ had the highest accumulation of pore water pressure while under the condition $b=0$ had the strongest resistance to the pore pressure generation. PWP accumulated mainly in the first cycle. The failure of specimens under principal stress rotation was controlled by the strain other than the pore pressure. The shear stiffness decreased more quickly with higher $b$ value. The direction of the principal strain increment was strongly dependent on the principal stress increment orientation and less influenced by the $b$ value and the number of cycles.
\end{abstract}

\section{Introduction}

Loading conditions in geotechnical engineering are very complex; therefore in laboratory test and numerical analysis the stresses on the soil elements need to well represent the real situation. In many scenarios, such as earthquakes, vehicular traffic, and ocean waves [1-3], not only the magnitude of principal stresses but also the direction will change. Studies on this kind of stress-induced anisotropy were stimulated and many were performed through laboratory test, where the volumetric strain and pore water pressure accumulation induced purely by principal stress rotation were highlighted [1-9].

In the literature, the principal stress (major and minor stress) rotated in the plane perpendicular to the intermediate principal stress direction. So the influence of intermediate principal stress, normally expressed by the intermediate principal stress parameter $b=\left(\sigma_{2}-\sigma_{3}\right) /\left(\sigma_{1}-\sigma_{3}\right)$, needs to be considered. The effect of $b$ on the soil response has been widely studied through many fixed principal stress direction tests. And the results showed that the shear strength, the pore pressure parameter, and the frictional angle of soils are highly dependent on the magnitude of $b$ [10-16].

However, the influence of $b$ has not been well studied in principal stress rotation tests. Ishihara and Towhata [1] were among the first to conduct undrained test of continuous principal stress rotation on sand by using a hollow cylinder apparatus (HCA). In all their tests, $b$ equaled to $\sin ^{2}(\alpha)$, where $\alpha$ is the angle between the directions of major principal stress and the vertical axis. This was due to the limitation of their apparatus [17]. So their study on principal stress rotation was not independent of $b$. Since then, pure principal stress rotation tests with constant mean total stress, $p$, the shear stress, $q$, and intermediate principal stress parameter, $b$, were carried out by others on sand and clay [2, 4-8], but most of the tests were conducted under the condition of $b=0.5$.

In recent years, the influence of $b$ on the sand behavior under the continuous principal stress rotation was studied experimentally by Yang et al. [2]. Undrained tests with pure principal stress rotation on the sand were conducted, $b$ values of $0,0.5$, and 1.0 were studied. The test results showed that $b$ 


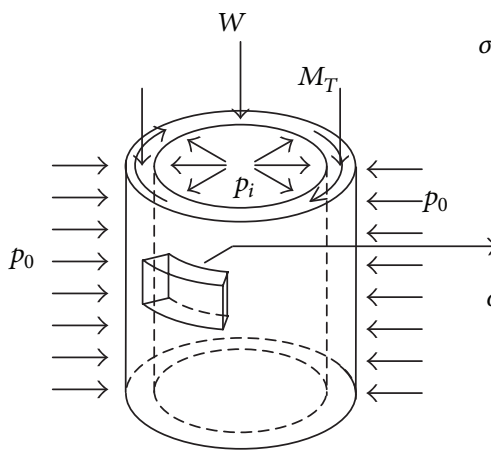

(a)

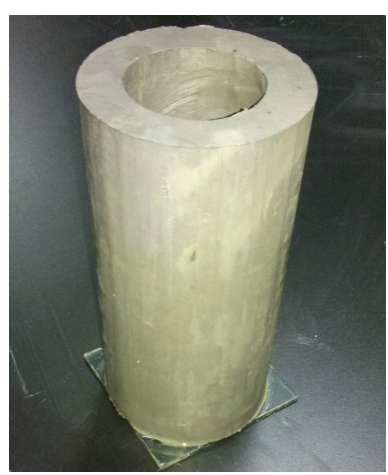

(b)

FIgURE 1: (a) Stress state of hollow cylinder specimens; (b) a completed hollow cylindrical specimen.

has great influence on the pore pressure and the deformation response during the pure principal stress rotation. The shear stiffness of sand decreased more quickly with cyclic principal stress rotation under $b=1.0$. Tests with identical stress paths under drained condition were carried out by Tong et al. [7]. The volumetric strain induced by the cyclic principal stress rotation accumulated more quickly under $b=1.0$. However, the direction of principal strain increment was less influenced by $b$.

In contrast with the relatively large number of studies on sand under the principal stress rotation, the response of intact clay to the pure principal stress rotation has received little attention. Tests on the intact Hangzhou soft clay under the pure principal stress rotation were presented in this study. A wide range of $b$ values $(0,0.25,0.5,0.75$, and 1.0$)$ were considered. The influence of $b$ as well as the shear stress was studied through the pore pressure evolution and the strain accumulation. The noncoaxial behavior and the stiffness degradation were also examined with the purpose of formulating more realistic constitutive models for clayey soil.

\section{Equipment and Test Scheme}

2.1. Hollow Cylinder Apparatus. Hollow cylinder apparatuses have been successfully used in the soil anisotropy studies. Here, different types of principal stress rotation tests on the intact Hangzhou soft clay were conducted using an advanced Zhejiang University hollow cylinder apparatus (ZJU-HCA). In this HCA the external loadings of axial load $W$, inner pressure $p_{i}$, outer pressure $p_{o}$, and torque $M_{T}$ can be applied and controlled individually to simulate the complex stress paths. The big advantage of simultaneously applying dynamic axial load and torque with a frequency up to $5 \mathrm{~Hz}$ provides many opportunities for the complex test. The maximum values of axial load and torque of ZJU-HCA are $12 \mathrm{kN}$ and $200 \mathrm{Nm}$.

The ZJU-HCA can be used for tests on both intact and reconstituted samples with the size of $160 \mathrm{~mm} \times 200 \mathrm{~mm} \times$ $400 \mathrm{~mm}$ and $60 \mathrm{~mm} \times 100 \mathrm{~mm} \times 200 \mathrm{~mm}$ (inner diameter $\times$ outer diameter $\times$ height), respectively. The details of this apparatus and the sampling kit can refer to Shen [18].
Corresponding to the axial load, inner cell pressure, outer cell pressure and torque, the stress components of $\sigma_{z}, \sigma_{r}$, $\sigma_{\theta}$, and $\tau_{z \theta}$ on the specimen indicated in Figure 1(a) can be calculated according to Hight et al. [19]. These four stress components can be converted into an equivalent set of four stress-related parameters, $p, q, \alpha$, and $b$ as the following:

$$
\begin{gathered}
p=\frac{\left(\sigma_{1}+\sigma_{2}+\sigma_{3}\right)}{3}=\frac{\left(\sigma_{z}+\sigma_{r}+\sigma_{\theta}\right)}{3} \\
q=\frac{\left(\sigma_{1}-\sigma_{3}\right)}{2}=\sqrt{\left(\sigma_{z}-\sigma_{\theta}\right)^{2} / 4+\tau_{\theta_{z}}^{2}} \\
\alpha=\frac{1}{2} \cdot \tan ^{-1}\left(\frac{2 \tau_{\theta z}}{\sigma_{z}-\sigma_{\theta}}\right) \\
b=\frac{\sigma_{2}-\sigma_{3}}{\sigma_{1}-\sigma_{3}} \\
\sqrt{\left(\left(2 \sigma_{r}-\sigma_{z}-\sigma_{\theta}\right) / 2\right)+\sqrt{\left(\left(\sigma_{z}-\sigma_{\theta}\right) / 2\right)^{2}+4 \tau_{\theta_{z}}^{2}}}
\end{gathered}
$$

where $p$ is the mean total stress, $q$ is the shear stress, $b$ is the intermediate principal stress parameter $(0 \leq b \leq 1)$, and $\alpha$ is the angle between the directions of the major principal stress and the vertical axis (Figure 1(a)). In this study the principal stresses $\left(\sigma_{1}\right.$ and $\left.\sigma_{3}\right)$ rotate in the plane perpendicular to $\sigma_{2}$.

As the four stress components of $\sigma_{z}, \sigma_{r}, \sigma_{\theta}$, and $\tau_{z \theta}$ can be controlled independently, stress paths with constants $p, q$, and $b$ while $\alpha$ increases continuously (pure principal stress rotation) can be achieved [18]. The main objective of this study is to investigate the influence of $b$ on the responses of intact soft clay under the pure principal stress rotation. This study can be well carried out with the support of ZJU-HCA.

2.2. Test Material and Sample Preparation. The hand-cut clay blocks were taken from an excavation pit $4 \mathrm{~m}$ below the ground level in Hangzhou; the basic physical properties of the clay are summarized in Table 1. After the hollow cylindrical specimen (Figure 1(b)) with the size of $100 \mathrm{~mm}$ in outer diameter, $60 \mathrm{~mm}$ in inner diameter and $200 \mathrm{~mm}$ in height was prepared by a special sampling kit [18]; filter paper strips were 
TABLE 1: Physical properties of the material.

\begin{tabular}{lccccc}
\hline Specific gravity: $G_{s}$ & Liquid limit: $w_{l}(\%)$ & $\begin{array}{c}\text { Plastic limit: } \\
w_{p}(\%)\end{array}$ & Plasticity index: $I_{p}$ & $\begin{array}{c}\text { Natural density: } \\
\rho\left(\mathrm{g} / \mathrm{cm}^{3}\right)\end{array}$ & $\begin{array}{c}\text { Natural water } \\
\text { content: } w(\%)\end{array}$ \\
\hline 2.68 & 49.8 & 22.8 & 27 & 1.78 & 42.2 \\
\hline
\end{tabular}

TABLE 2: Test program of pure principal stress rotation.

\begin{tabular}{lccc}
\hline Test no. & $q / \mathrm{kPa}$ & $b$ & $\alpha /^{\circ}$ \\
\hline Series 1 & & & \\
RS3700 & 37.5 & 0 & $0 \sim 360$ \\
RS3725 & 37.5 & 0.25 & $0 \sim 360$ \\
RS3705 & 37.5 & 0.5 & $0 \sim 360$ \\
RS3775 & 37.5 & 0.75 & $0 \sim 360$ \\
RS3710 & 37.5 & 1 & $0 \sim 360$ \\
Series 2 & & & \\
RS2510 & 25 & 1 & $0 \sim 360$ \\
RS3710 & 37.5 & 1 & $0 \sim 360$ \\
RS5010 & 50 & 1 & $0 \sim 360$ \\
RS5010-2 & 50 & 1 & $90 \sim 270$ \\
Series 3 & & & $0 \sim 360$ \\
RS2505 & 25 & 0.5 & $0 \sim 360$ \\
RS3705 & 37.5 & 0.5 & \\
\hline
\end{tabular}

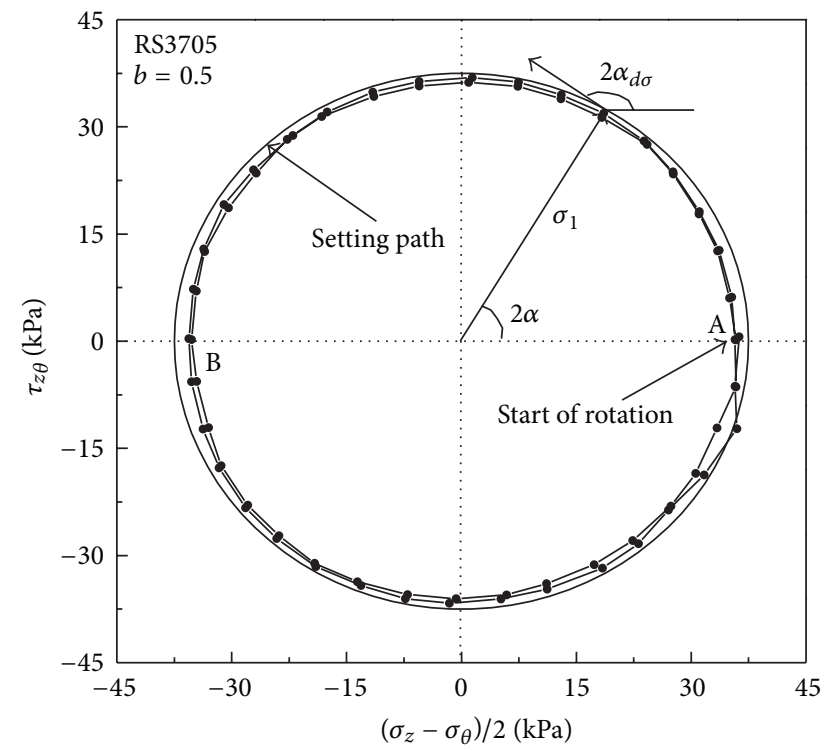

FIGURE 2: Stress path of pure principal stress rotation.

pasted around the outer surface of the specimen to equalize pore water pressure and reduce the consolidation time. After that, the specimen was assembled into the cell to be saturated with a backpressure of $100 \mathrm{kPa}$, ensuring the Skempton's pore pressure parameter $B$ higher than 0.98. After saturation the specimens were isotropically consolidated under an effective pressure of $150 \mathrm{kPa}$.

2.3. Test Plan. In this study $\alpha$ was increased up to $360^{\circ}$ to highlight the first two cycles (principal stress rotated $180^{\circ}$ in each cycle), since the soil response to the pure principal stress rotation was mainly embodied in the first several cycles, as manifested in the documents $[2,6,7]$. Nine tests were conducted and divided into three series according to the magnitudes of $q$ and $b$. After the accomplishment of consolidation, $b$ and shear stress $q$ gradually increased to the values listed in Table 2 under undrained condition and constant $p=150 \mathrm{kPa}$ to point $\mathrm{A}$ in Figure 2. The torque was applied with an angular displacement rate of $0.2^{\circ} / \mathrm{min}$ (corresponding to a shear stress rate of $2.8 \times 10^{-3} \mathrm{kPa} / \mathrm{sec}$ ) when pore water pressure equalized. All the tests followed the same procedure except test RS5010-2, which was sheared from $\alpha=90^{\circ}$ (point B in Figure 2) and stopped earlier due to the failure. The stress path of pure principal stress rotation in the stress plane of $\left(\sigma_{z}-\sigma_{\theta}\right) / 2 \sim \tau_{z \theta}$ is illustrated in Figure 2, the setting stress path can be carried out by the HCA with an acceptable accuracy.

Stress components need to be well designed to perform pure principal stress rotation test. The corresponding stress paths were realized by simultaneous change of $\sigma_{z}, \sigma_{\theta}$, and $\tau_{z \theta}$ with $\alpha$, and keeping constant radial stress $\sigma_{r}$ (Figure 3(a)). according to the equations of (1). The variation of stress components of $\sigma_{z}, \sigma_{r}, \sigma_{\theta}$, and $\tau_{z \theta}$ during principal stress rotation with constant $p, q$, and $b$ can be determined

$$
\begin{gathered}
\sigma_{z}=p-\frac{2 b q-q}{3}+q \cos 2 \alpha, \\
\sigma_{r}=p+\frac{2(2 b q-q)}{3}, \\
\sigma_{\theta}=p-\frac{2 b q-q}{3}-q \cos 2 \alpha, \\
\tau_{z \theta}=q \sin 2 \alpha .
\end{gathered}
$$

Figure 3 shows the variation of the stress components and the principal stresses with rotation in test RS3705. The variations of stress components of $\sigma_{z}, \sigma_{\theta}$, and $\tau_{z \theta}$ all follow the equations of (2)-(5). Stress responses in Figure 3 also demonstrate the reliability and accuracy of the apparatus.

2.4. Repeatability of Test. Two parallel tests on the reconstituted clay were carried out despite the fact that the transducers in the ZJU-HCA have very good sensitivity and high resolution. The reconstituted clay was made from slurry being isotropically consolidated with a vacuum pressure of $65 \mathrm{kPa}$ in a patented reconstitution device [20]. Two specimens $R 1$ and $R 2$ were prepared and consolidated at an effective pressure of $150 \mathrm{kPa}$. Subsequently undrained shear test was performed under $b=0.5$. First the shear stress was increased to $q=25 \mathrm{kPa}$ ( $\mathrm{AB}$ in Figure $4(\mathrm{a})$ ), then the major principal stress axes rotated from $0^{\circ}$ to $90^{\circ}$ (BC in Figure $4(\mathrm{a})$ ), and 


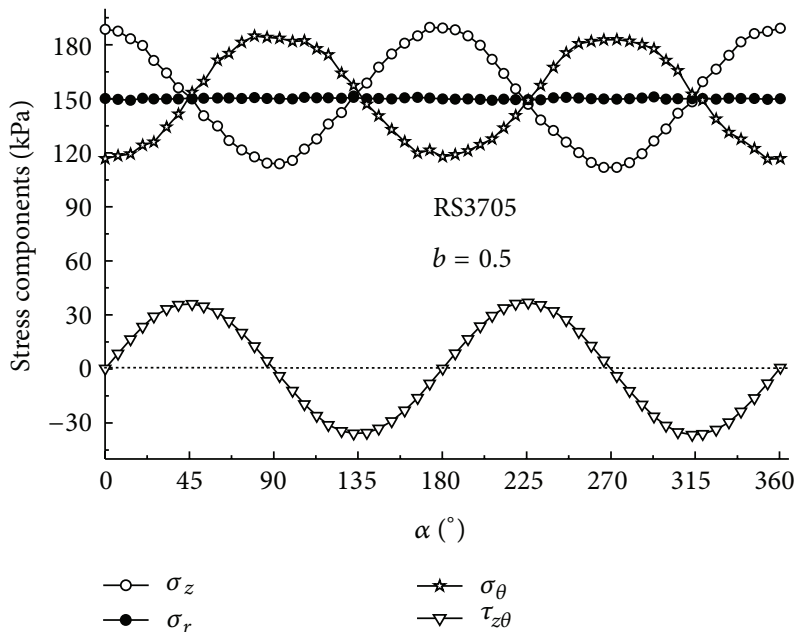

(a)

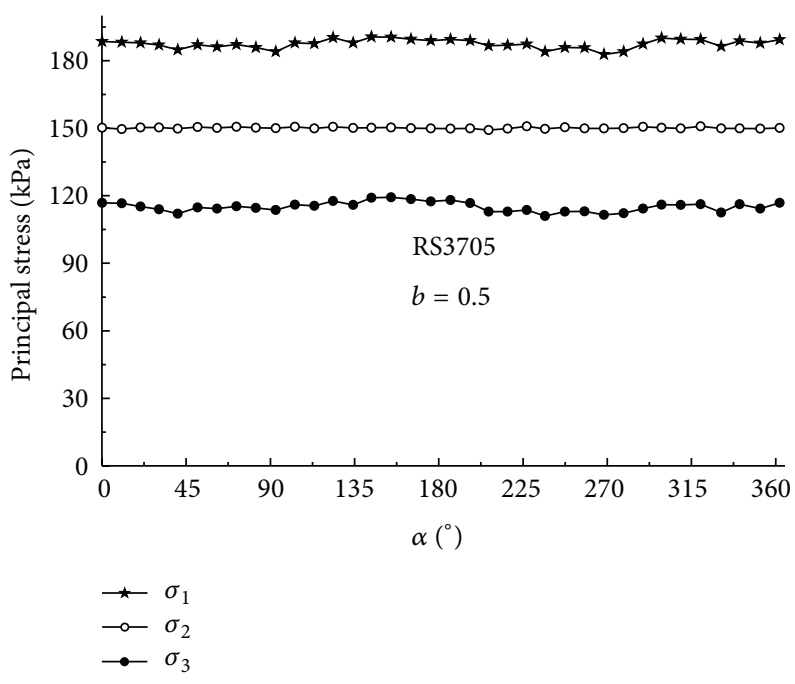

(b)

FIgURE 3: Variation in stress components (a) and principal stresses (b) of RS3705.

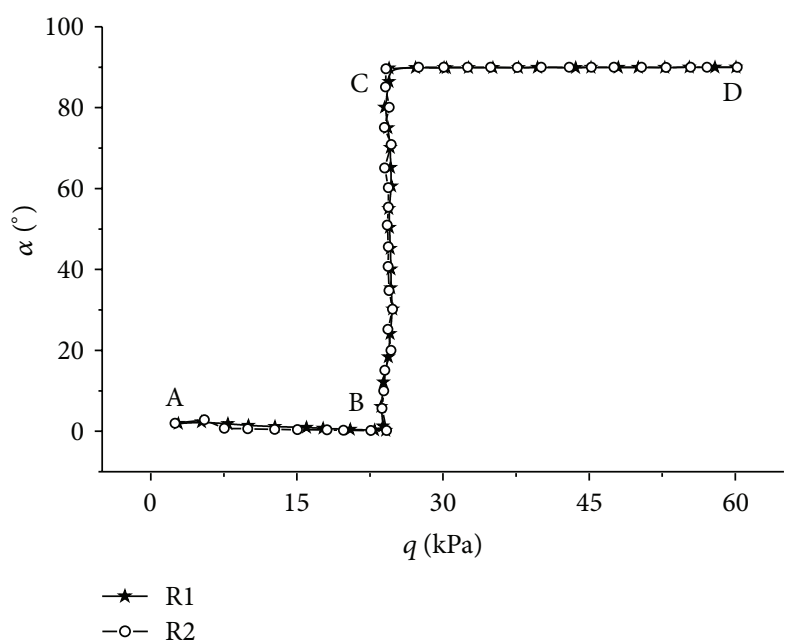

(a)

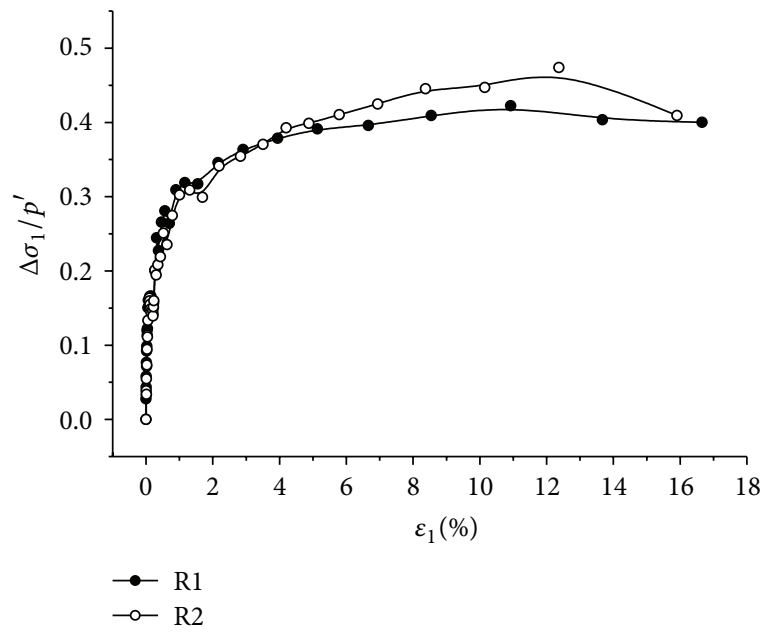

(b)

Figure 4: (a) Stress path of $R 1$ and $R 2$; (b) $\Delta \sigma_{1}-\Delta \varepsilon_{1}$ curves of $R 1$ and $R 2$.

finally the specimens were sheared to failure with $\alpha$ fixed at $90^{\circ}$ (CD in Figure 4(a)). Two tests had identical stress path, as illustrated in Figure 4(a). During the whole test, the magnitude of $p$ was kept constant at $150 \mathrm{kPa}$.

The stress-strain curves of the two tests had good consistency, especially at small strain stage, as shown in Figure 4(b). Some divergence was observed as specimens approaching failure at large strain. This result provided strong evidence of the acceptable repeatability of this apparatus, and the negligible effect of the specimen preparation and assembling.

\section{Test Results and Discussion}

3.1. Evolution of Pore Water Pressure. Although the shear stress $q$ was constant in pure rotation tests, significant pore water pressure (PWP for short) accumulated with the principal stress rotation (Figure 5), which surely demonstrated the effect of the intermediate principal stress. Clear fluctuation was observed in PWP, which was in agreement with the test results from sand $[2,6]$. The fluctuation was not significant in the first cycle as compared with the second. In the first cycle PWP accumulation was approximately double that of the second cycle. Table 3 shows PWP increments during $\alpha=$ $0^{\circ} \sim 90^{\circ}$ and $\alpha=90^{\circ} \sim 180^{\circ}$ in each cycle of series 1 . Most PWP accumulation generated during the stage when $\alpha$ increased from $90^{\circ}$ to $180^{\circ}$ and PWP reached a peak value at the end of each cycle $\left(\alpha=180^{\circ}\right)$.

The effect of $b$ values on PWP accumulation with $\alpha$ in the series 1 is presented in Figure 5(a). As it shows, the mode of PWP accumulation with $\alpha$ under different $b$ was similar. 


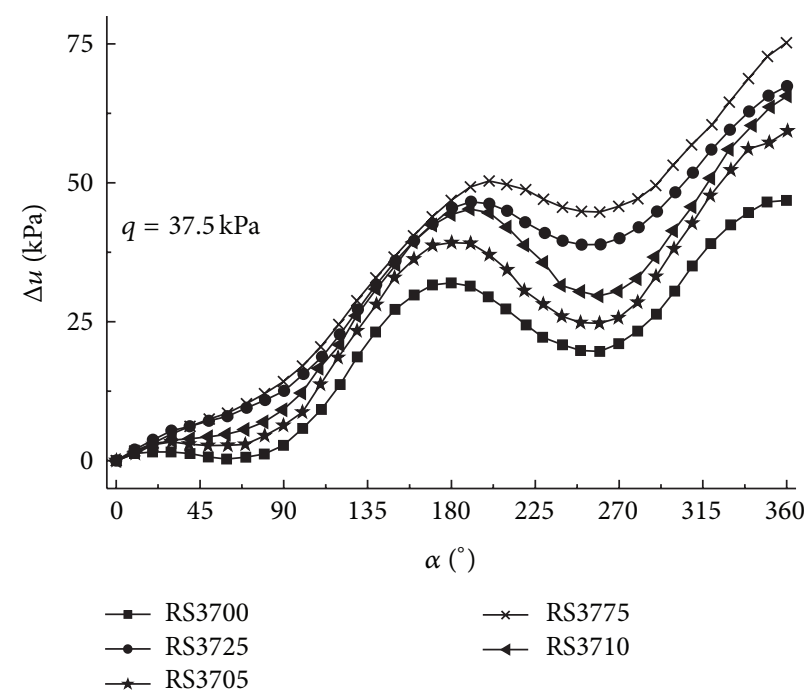

(a)

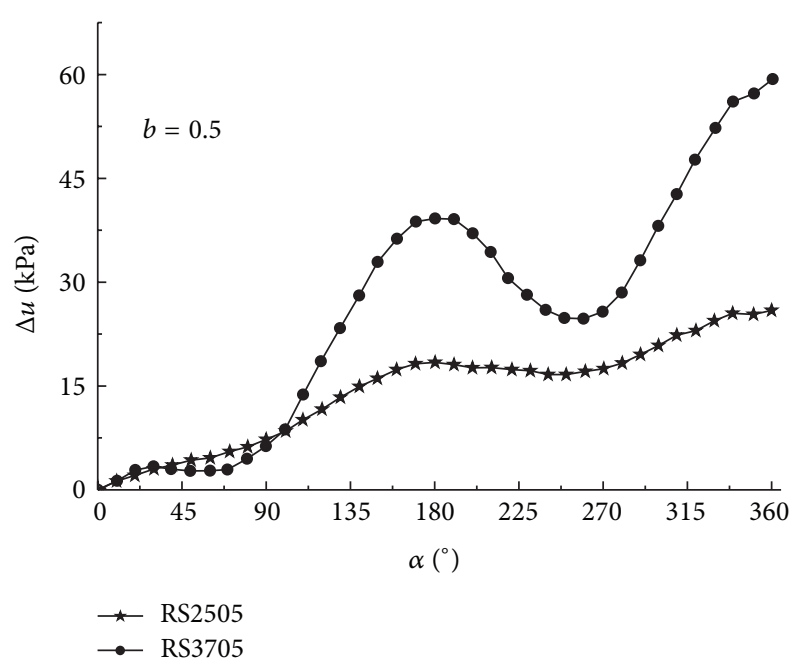

(c)

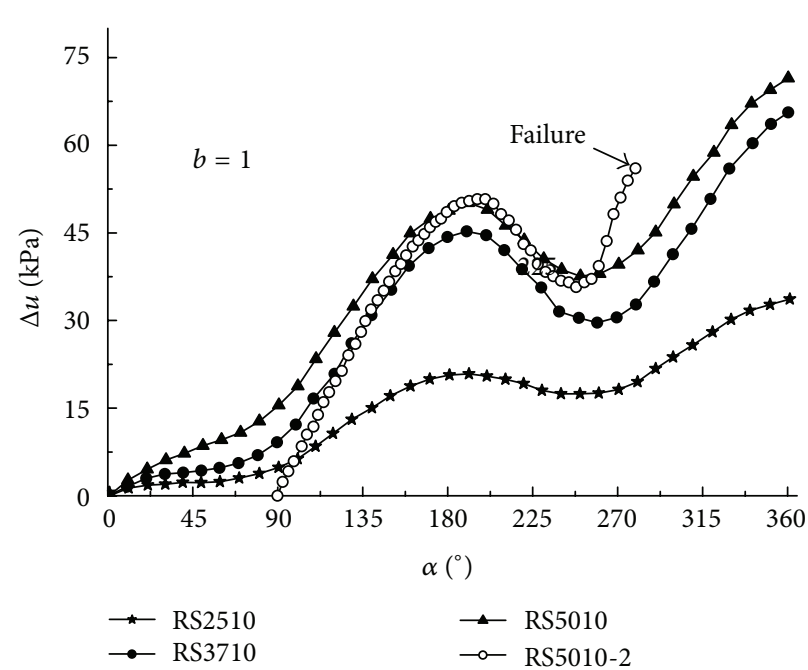

(b)

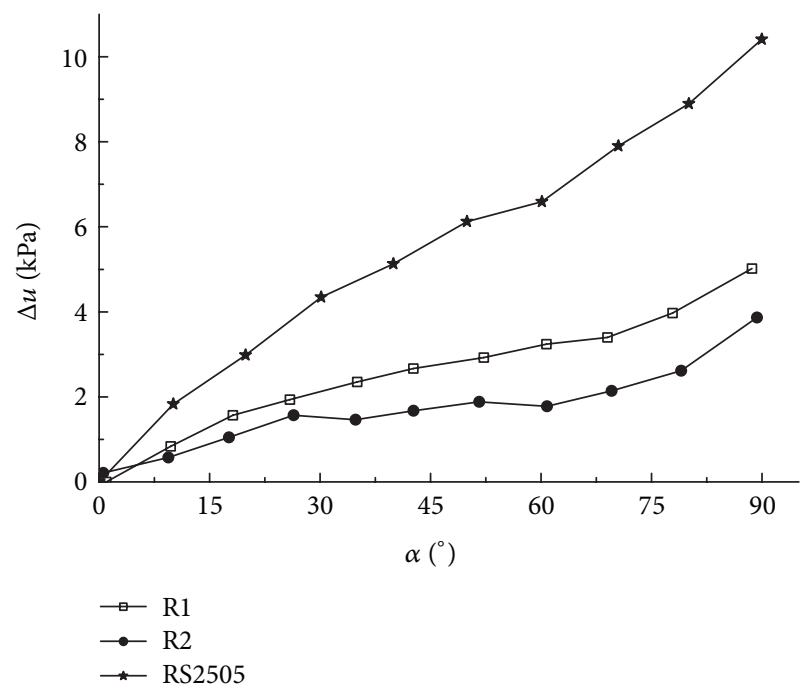

(d)

FIgURE 5: Pore water pressure accumulation with $\alpha$ : (a) series 1; (b) series 2; (c) series 3; (d) R1, R2, and RS2505.

However, the rate of accumulation was affected significantly by $b$. PWP accumulation under the conditions $b=0.75$ and $b=0.25$ were larger than that under the conditions $b=0,0.5$ and 1.0. And specimen in the test under $b=0$ had the lowest accumulation of pore water pressure; this observation is also consistent with the test results from sand [2]. The fact that the PWP not monotonously increasing with $b$ suggests that the influence of $b$ is more complex; it could not be fully revealed if only a limited range of $b$ values were considered.

The effect of shear stress on PWP is much pronounced, as illustrated in Figures 5(b) and 5(c). PWP increased rapidly with large shear stress. The difference in PWP accumulation between the tests at $q=50 \mathrm{kPa}$ and $q=37.5 \mathrm{kPa}$ was smaller than that between the tests at $q=25 \mathrm{kPa}$ and $q=$ $37.5 \mathrm{kPa}$ in series 2 under the condition $b=1.0$. Undrained rotational shear tests on sand [2] had same observation that the influence of shear stress on PWP reduces when the value of shear stress increased.

Test RS5010-2 had the same stress path as test RS5010 except that principal stress rotated from $\alpha=90^{\circ}$ instead of $\alpha=0^{\circ}$. It is interesting to note that the peak value of PWP in test RS5010-2 had nearly the same magnitude and occurred at the same direction (at $\alpha=180^{\circ}$ ) as the test RS5010. Moreover, the PWP generation in test RS5010 and test RS5010-2 were still very close when $\alpha=180^{\circ} \sim 250^{\circ}$, which clearly shows that PWP build-up during rotational shear is less dependent on the initial direction of principal stress. The PWP accumulation in RS5010-2 also supports the observations that PWP generated mainly during the period of $\alpha=90^{\circ} \sim 180^{\circ}$.

When $\alpha=250^{\circ}$ the PWP of RS5010-2 increased abruptly and the specimen failed with large deformation at $\alpha=270^{\circ}$. 


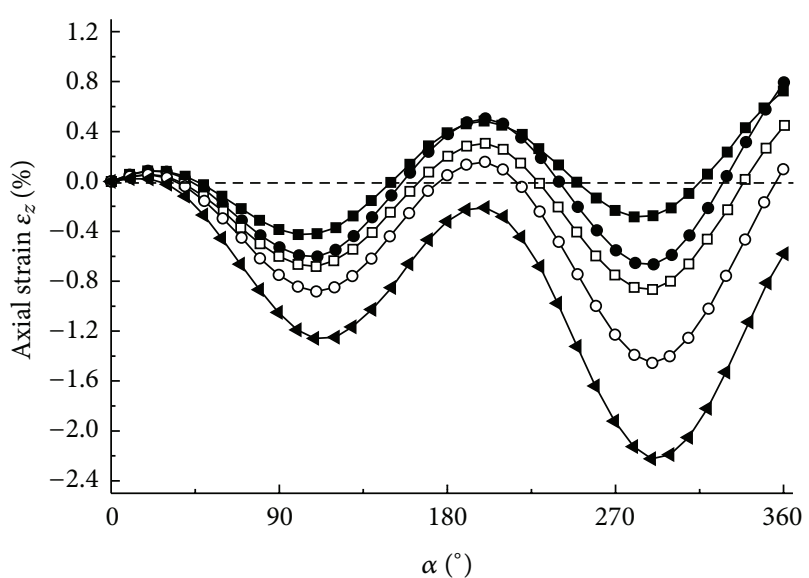

(a)

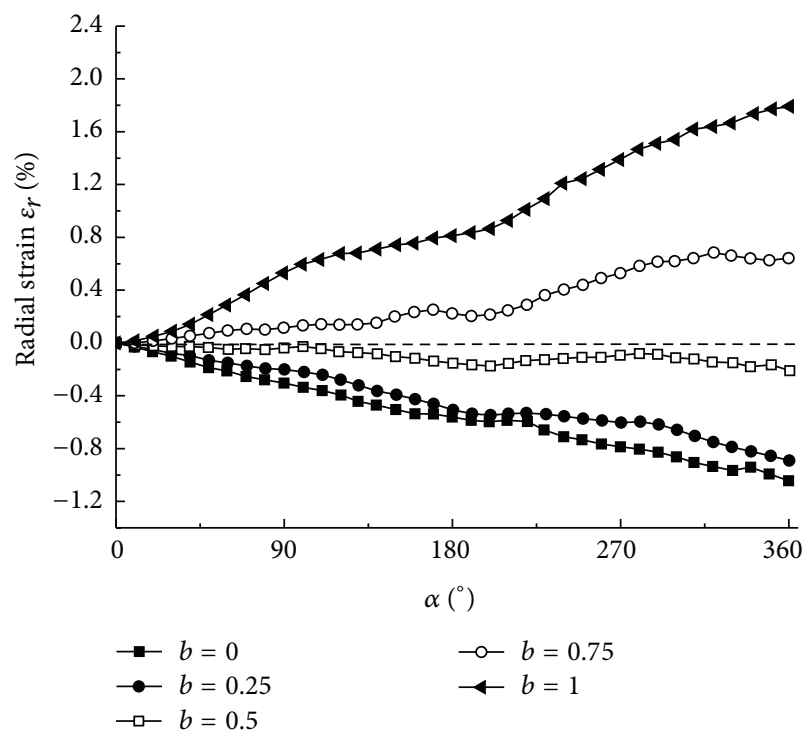

(c)

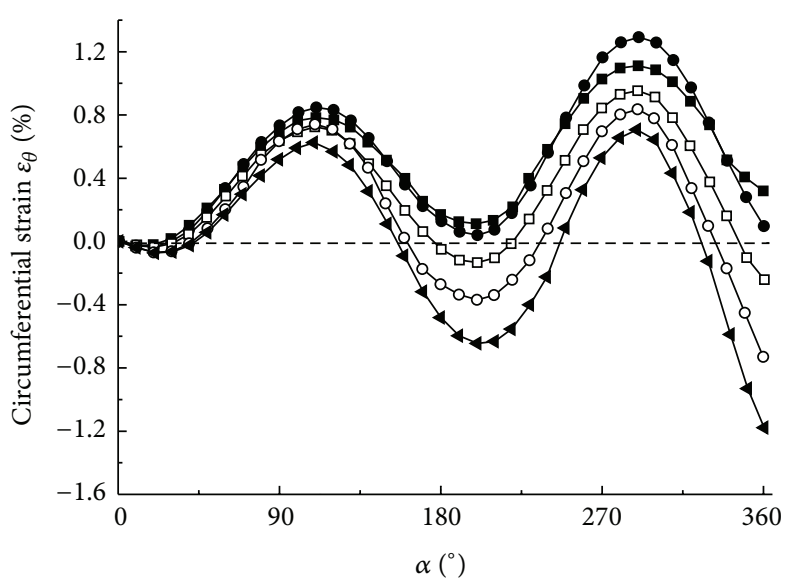

(b)

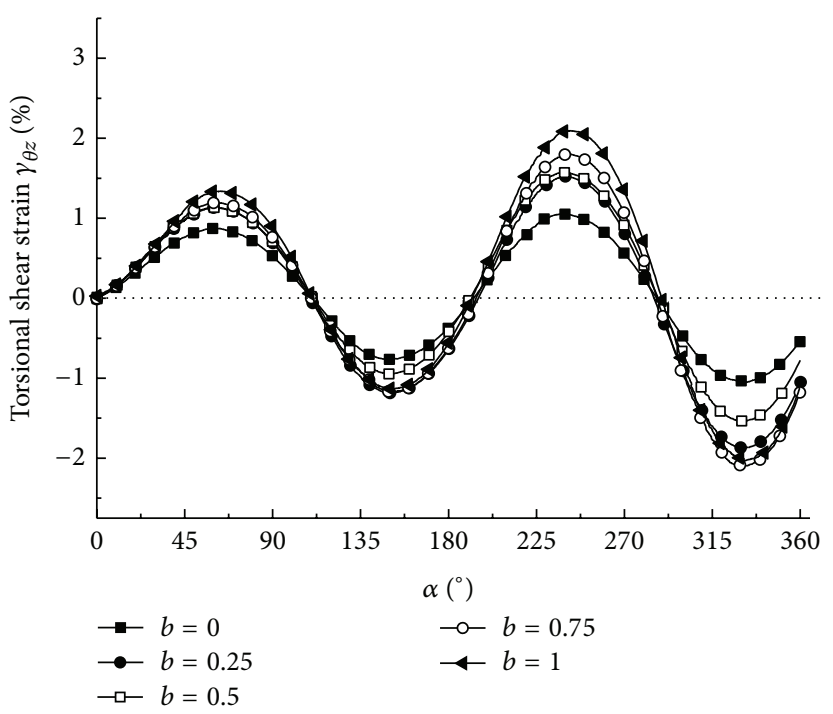

(d)

FIGURE 6: Variation in strain components with $\alpha$ in series 1: (a) axial strain; (b) circumferential strain; (c) radial strain; (d) torsional shear strain.

TABLE 3: PWP increment of series 1.

\begin{tabular}{llccc}
\hline \multicolumn{5}{c}{ PWP increment $\Delta u / \mathrm{kPa}$} \\
Test no. & Cycles & $\alpha=0^{\circ}-90^{\circ}$ & $\alpha=90^{\circ}-180^{\circ}$ & $\sum$ \\
\hline \multirow{2}{*}{ RS3700 } & $\Delta u_{\text {cycle 1 }}$ & 3.03 & 28.96 & 31.99 \\
& $\Delta u_{\text {cycle 2 }}$ & -10.77 & 25.61 & 14.84 \\
\hline \multirow{2}{*}{ RS3725 } & $\Delta u_{\text {cycle 1 }}$ & 12.7 & 32.78 & 45.48 \\
& $\Delta u_{\text {cycle 2 }}$ & -5.49 & 27.49 & 22 \\
\hline \multirow{2}{*}{ RS3750 } & $\Delta u_{\text {cycle 1 }}$ & 6.33 & 33.04 & 39.37 \\
& $\Delta u_{\text {cycle 2 }}$ & -13.28 & 33.09 & 19.81 \\
\hline \multirow{2}{*}{ RS3775 } & $\Delta u_{\text {cycle 1 }}$ & 14.28 & 32.73 & 47.01 \\
& $\Delta u_{\text {cycle 2 }}$ & -1.15 & 29.49 & 28.34 \\
\hline \multirow{2}{*}{ RS3710 } & $\Delta u_{\text {cycle 1 }}$ & 9.46 & 34.82 & 44.28 \\
& $\Delta u_{\text {cycle 2 }}$ & -13.75 & 35.13 & 21.38 \\
\hline
\end{tabular}

The PWP value at failure point was far smaller than the initial confining pressure $(150 \mathrm{kPa})$, which implies that the failure in undrained pure principal stress rotation test is mainly controlled by strain, not PWP accumulation.

PWP accumulation in reconstituted sample was quite different from the intact sample. Figure 6(d) shows the comparison of PWP accumulation in tests $R 1, R 2$ (reconstituted), and RS2505 (intact). These tests started from the same stress state $(b=0.5, q=25 \mathrm{kPa})$ and experienced the same rotation stress path (from $0^{\circ}$ to $90^{\circ}$ ), but PWP in intact clay had higher developing rate and larger accumulation than the reconstituted ones. This is attributed to the inherent anisotropy of the intact sample. Here, it has to note that even in reconstituted specimens, which is normally treated as isotropic material [9], PWP still accumulated and was approximately $40 \%$ of the intact one. This phenomenon is very important and it indicates that even the changes in the direction of principal stress could lead to pore water pressure accumulation, which further causes soil degradation. This potential risk cannot be underestimated in practical design. 


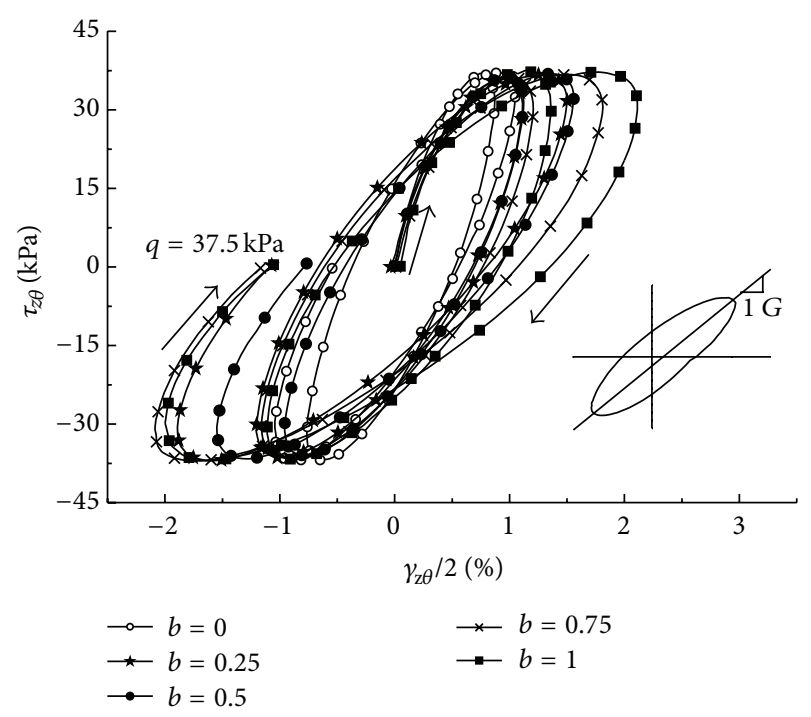

FIGURE 7: Shear stress-strain relationship of series 1.

3.2. Variation of Strain Components. Pure principal stress rotation test was performed under constants $p, q$, and $b$; however strain development was still significant. Figure 6 presents strain development in series 1 test (take compression as positive). Strain components of $\varepsilon_{z}, \varepsilon_{\theta}$, and $\gamma_{z \theta}$ had cyclic variation with $\alpha$ however the variation of stress and strain components was not synchronous. Development of $\varepsilon_{z}, \varepsilon_{\theta}$, and $\gamma_{z \theta}$ lagged $20^{\circ}$ behind the corresponding stresses. For example, the torsional shear stress $\tau_{z \theta}$ reached the peak value at $\alpha=45^{\circ}$ (Figure 3(a)), but $\gamma_{z \theta}$ approached peak value until $\alpha=65^{\circ}$. That was the evidence of the noncoaxiality between the directions of the principal stress and the principal strain increment also found in sand [4, 5, 7] and will be discussed later. It is also clear that strain accumulation in the second cycle was larger than that in the first cycle, which was different from the PWP evolution.

The variation of strain components $\left(\varepsilon_{z}, \varepsilon_{\theta}, \gamma_{z \theta}\right.$, and $\left.\varepsilon_{r}\right)$ with $\alpha$ were very similar under smaller $b$, such as the cases $b=$ 0 and $b=0.25$. The effect of $b$ increased with the magnitude, as clearly shown in $\varepsilon_{z}$ in Figure 6(a). As $b$ increased, that is the influence of radial stress $\sigma_{r}$ increased (see, (3)), radial strain increased. Due to larger radial stress the influence of other stress on the corresponding strain decreased, and soil samples exhibited less compression, but more dilation. Similar situation also happened in $\varepsilon_{\theta}$ and $\gamma_{z \theta}$ (Figures 6(b) and $6(\mathrm{~d}))$. Compared with $\varepsilon_{z}$ and $\varepsilon_{\theta}$, the impact of $b$ on $\gamma_{z \theta}$ was relatively small (shown in Figure 6(d)).

Other than the oscillation in $\varepsilon_{z}, \varepsilon_{\theta}$ and $\gamma_{z \theta}$, approximately a linear relationship between $\varepsilon_{r}$ and $\alpha$ was observed, which supported the fact that the variation of $\alpha$ was independent of $\sigma_{r}$. The increasing $\varepsilon_{r}$ was induced by plastic deformation. In Figures 6(a), 6(b), and 6(d) irrecoverable strain at the end of each cycle was also noticed, which meant plastic deformation could be generated by the changes of principal stress direction alone. Results in this paper also indicate that the rate of strain development in clayey soil was much higher than sandy material $[2,5,6]$ when soil samples experienced identical stress path and similar stress level.

It needs to mention that when $b=0.5$ very small radial strain developed during the whole rotation (seen in Figure 6(c)). This indicates that the assumption of plane strain condition is reasonable when $b=0.5$.

Shear stress-strain relationship of series 1 is given in Figure 7. The unclosed hysteretic loops manifest the accumulation of plastic strain. Shear stiffness $G$, defined as the secant modulus of shear stress-strain loops [2], also affected by $b$, as shown in Figure 7. Though specimens only experienced two cycles of principal stress rotation, significant stiffness degradation can be observed, and degradation was more significant as $b$ increased. This observation agrees well with the tests on sand [2].

The influence of shear stress on strain components is much larger than $b$ value. In series 2 the shear stress in test RS5010 was two times of test RS2510, but the magnitude of strain components was ten times larger, as seen in Figures 8(a) and 8(b). Horizontal symmetry was found in $\varepsilon_{z}$ and $\varepsilon_{\theta}$ in the condition of low shear stress and small rotation range. Same phenomenon was observed in drained tests on Toyoura dense sand (Miura et al. [5]) and undrained tests on intact clay (Zhou and $\mathrm{Xu}[21]$ ). However the behavior of symmetry was affected as $\alpha$ increased. With the rapid development of strain in high shear stress test, this phenomenon was not obvious, such as test RS5010-2. Specimen of RS5010-2 experienced identical stress path as RS5010 except the initial direction of principal stress. The different responses in strain components illustrate that the initial principal stress direction had significant influence on the deformation behavior of intact clay under pure principal stress rotation. Compared with test RS5010, RS5010-2 approached earlier failure and the radial and axial strain increased dramatically at the onset of failure (Figure 8(c)). This strain development is consistent with the development of pore pressure as given in Figure 5(b). However, the effect of initial rotation direction on the following behavior has not caused attention.

3.3. Noncoaxial Behavior of Intact Clay. As was observed in lots of experimental researches, the direction of the principal strain increment has no coincidence with the principal stress direction during the principal stress rotation [5, 7, 22-25]. The deviation between them is defined as the noncoaxial behavior of soils $[23,24]$, which can be described by the noncoaxial angle of $\beta=\left(\alpha_{d \varepsilon}-\alpha\right)$. Where $\alpha_{d \varepsilon}$ is the direction of the principal strain increment from the vertical axis of the specimen, it can be expressed as

$$
\alpha_{d \varepsilon}=\frac{1}{2} \arctan \left(\frac{\mathrm{d} \gamma_{z \theta}}{\mathrm{d} \varepsilon_{z}-\mathrm{d} \varepsilon_{\theta}}\right),
$$

where $\mathrm{d} \varepsilon_{z}, \mathrm{~d} \varepsilon_{\theta}$, and $\mathrm{d} \gamma_{z \theta}$ are the increment of axial strain, circumferential strain and torsional shear strain, respectively.

The variation of noncoaxial angle in series 1 is presented in Figure 9. It can be found that the noncoaxial behavior of intact clay was obvious in the pure principal rotation test. The variation of $\beta$ with $\alpha$ in both cycles was similar (Figures 9(a) and 9(b)), and the noncoaxiality was less affected by 


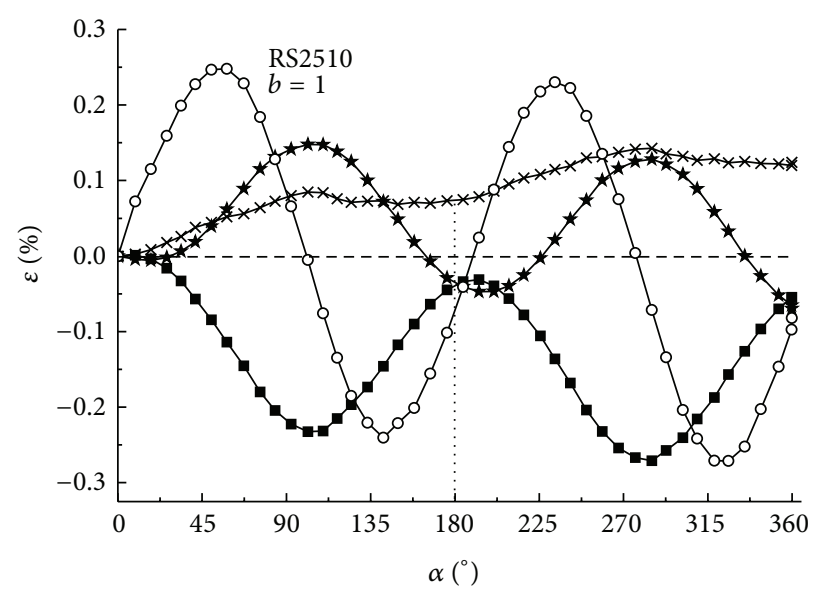

(a)

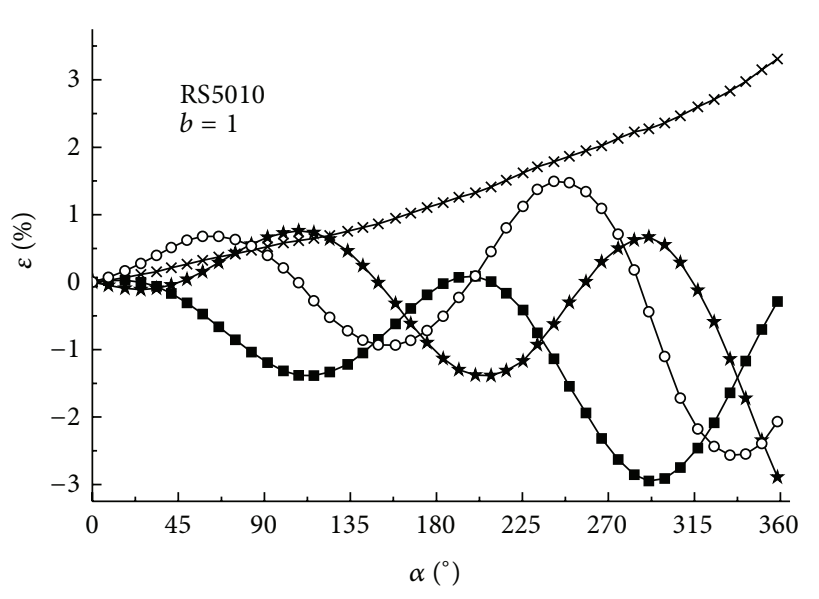

(b)

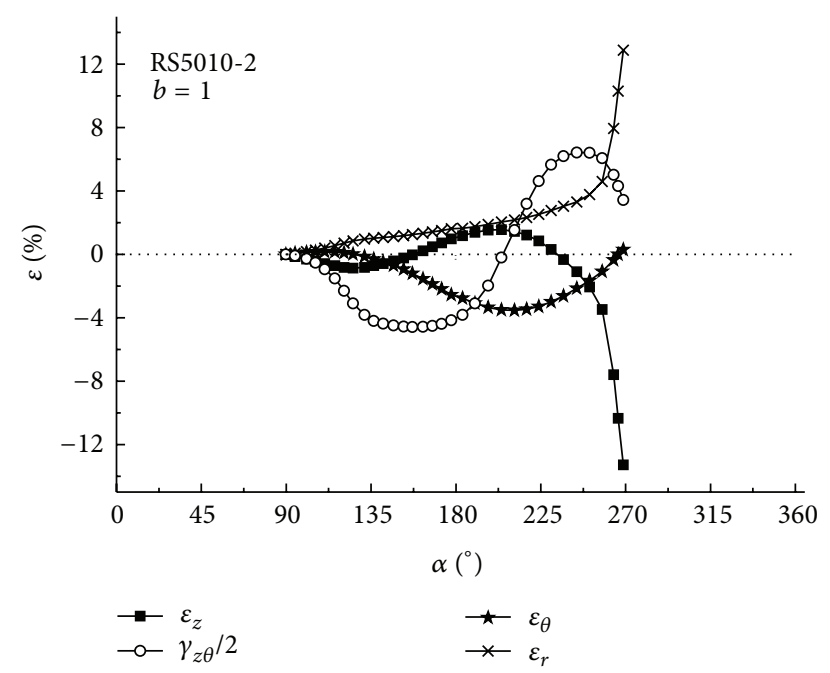

(c)

FIGURE 8: Variation of strain components with $\alpha$ in series 2: (a) RS2510; (b) RS5010; (c) RS5010-2.

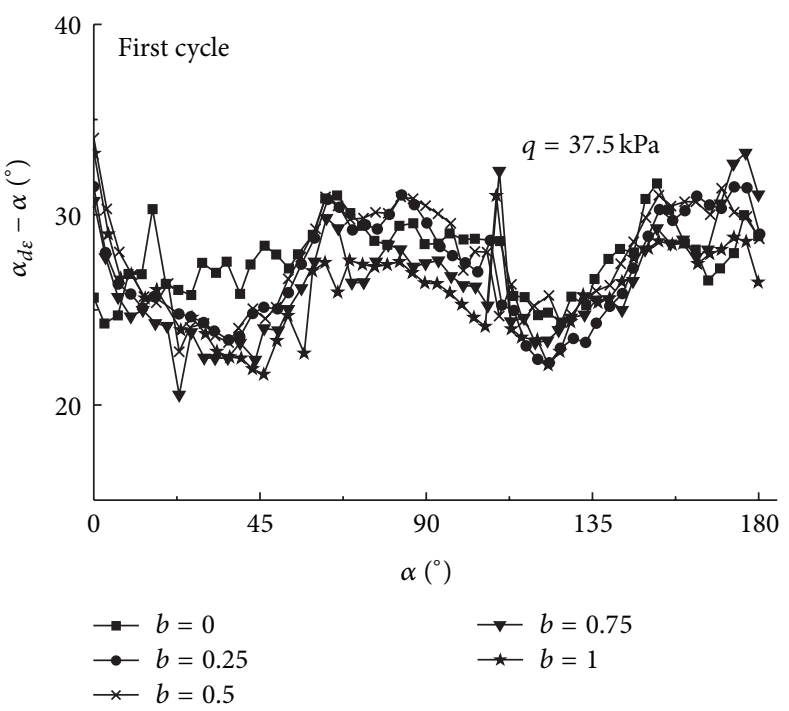

(a)

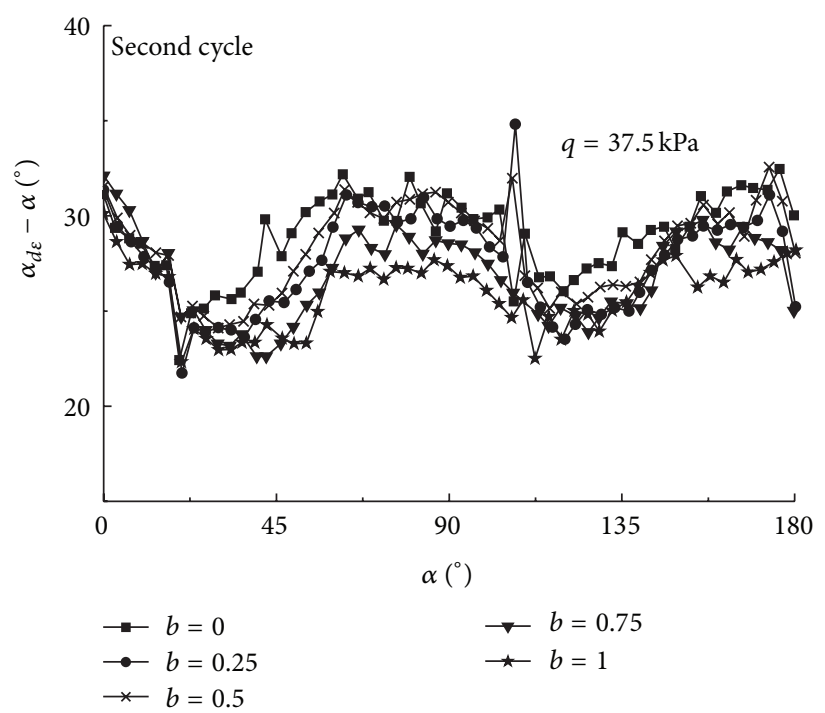

(b)

Figure 9: Variation of $\beta=\left(\alpha_{d \varepsilon}-\alpha\right)$ with $\alpha$ of series 1: (a) First cycle; (b) Second cycle. 


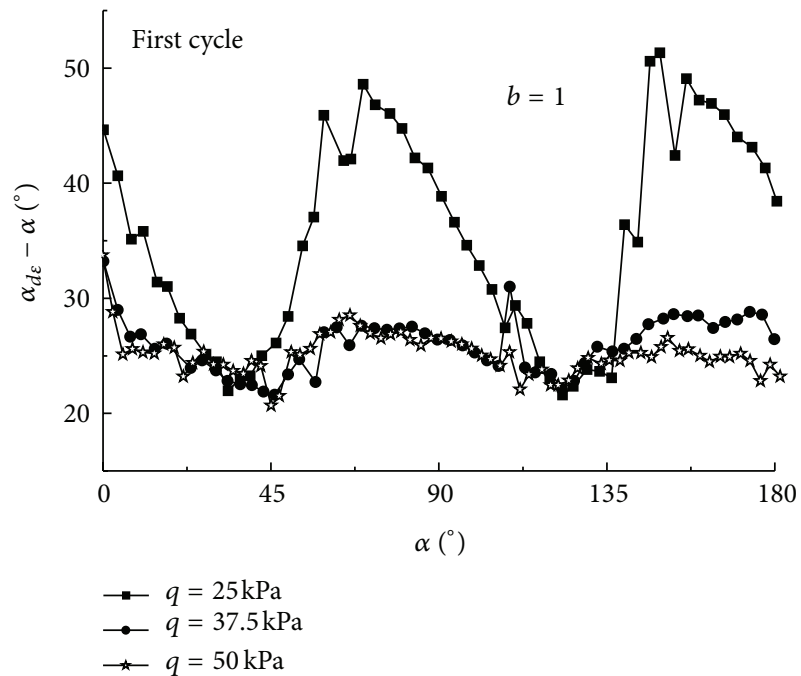

(a)

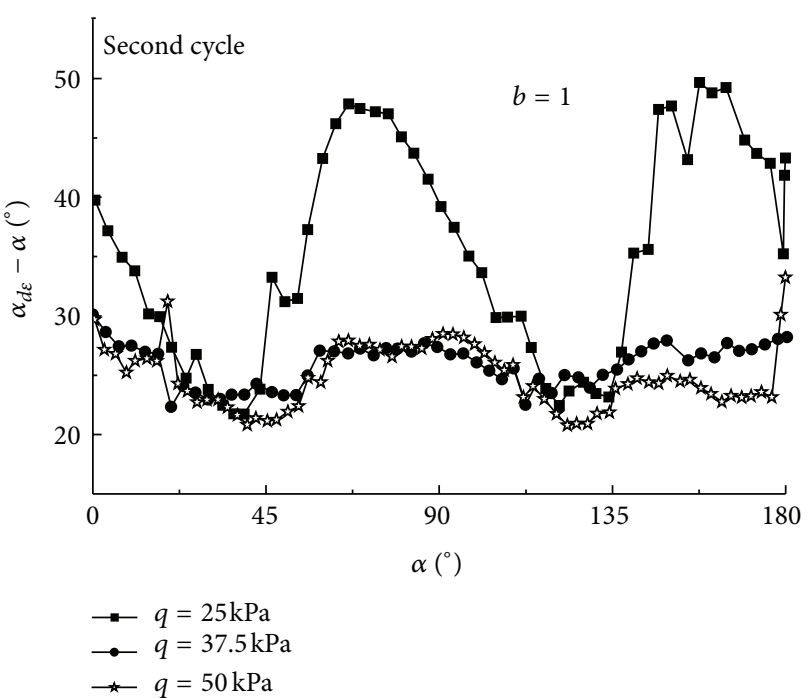

(b)

FIGURE 10: Variation of $\beta=\left(\alpha_{d \varepsilon}-\alpha\right)$ with $\alpha$ of series 2: (a) first cycle; (b) second cycle.

the number of rotation cycles. Nevertheless there was some fluctuation in $\beta$. $\beta$ decreased with $\alpha$ when $\alpha$ rotated from $0^{\circ}$ to $40^{\circ}$ and from $90^{\circ}$ to $120^{\circ}$. Tong et al. [7] had the same observation from their drained test on sand. When $\alpha$ rotated from $45^{\circ}$ to $80^{\circ}$ and from $120^{\circ}$ to $180^{\circ}$, results were very different; that is, $\beta$ increased with $\alpha$ in this research, while $\beta$ kept constant $\left(\beta=45^{\circ}\right)$; in their tests. In general, it was found that noncoaxiality existed along the whole test procedure with clayey soil. Despite of the fluctuation between $22^{\circ}$ and $30^{\circ}$, the average $\beta$ value can be taken as $27^{\circ}$.

Experimental study in this research also shows that the noncoaxiality of intact clay was influenced by the shear stress rather than the intermediate principal stress (illustrated in Figure 10). In series $2, \beta$ also fluctuated with $\alpha$, but the amplitude was mainly controlled by the shear stress. The noncoaxial angles of specimens in the cases of $q=37.5 \mathrm{kPa}$ and $q=50 \mathrm{kPa}$ were very close in both cycles. However, the noncoaxial angles in the case of $q=25 \mathrm{kPa}$ were dramatic, this is consistent with the test result from sand by Cai [24]. As pointed out by Miura et al. [5], Pradel et al. [26], and Ohkawa et al. [27] that the direction of the principal strain increment was strongly dependent on the stress path (direction of stress increment), this study also concluded that noncoaxiality is very significant in complex stress path test and the associated flow rule is no longer applicable.

\section{Conclusions}

A series of pure principal stress rotation tests on intact soft clay were conducted by using the ZJU-5 Hz hollow cylinder apparatus in this study. The magnitude of mean total stress $p$, intermediate principal stress parameter $b$ and shear stress $q$ were all maintained constant during rotation. The influence of $b$ on the response of pore water pressure and deformation behavior was focused and the main conclusions can be drawn as follows.
(1) Significant pore water pressure accumulation was observed in pure principal stress rotation test. PWP accumulated mainly when $\alpha$ increased from $90^{\circ}$ to $180^{\circ}$ and most of the accumulation generated in the first cycle.

(2) The rate of PWP evolution was greatly influenced by $b$, but the influence was not monotonous. Specimens under the condition $b=0$ had the lowest PWP accumulation, while the highest accumulation occurred under the condition $b=0.75$. PWP accumulation was less influenced by the previous stress path.

(3) Development of strain components induced by pure principal stress rotation was affected by the magnitudes of $b$ and $q$. Specimen can also fail in pure principal stress rotation test due to large deformation. Shear stiffness decreased with principal stress rotation, and it decreased quickly with large $b$.

(4) The deviation between the principal stress and the principal strain increment directions existed in the course of the test. The strain increment direction was strongly dependent on the direction of stress increment. Noncoaxial angles had some fluctuation and the average angle was $27^{\circ}$ in this research. Noncoaxial character of intact soft clay under pure principal stress rotation was less influenced by $b$ and the number of cycles.

\section{Acknowledgment}

The financial support provided by the National Natural Science Foundation of China (no. 51178422 and no. 51338009) is gratefully acknowledged. 


\section{References}

[1] K. Ishihara and I. Towhata, "Sand response to cyclic rotation of principal stress directions as induced by wave loads," Soils and Foundations, vol. 23, no. 4, pp. 11-26, 1983.

[2] Z. X. Yang, X. S. Li, and J. Yang, "Undrained anisotropy and rotational shear in granular soil," Geotechnique, vol. 57, no. 4, pp. 371-384, 2007.

[3] P. J. Gräbe and C. R. I. Clayton, "Effects of principal stress rotation on permanent: deformation in rail track foundations," Journal of Geotechnical and Geoenvironmental Engineering, vol. 135, no. 4, pp. 555-565, 2009.

[4] M. J. P. R. Symes, A. Gens, and D. W. Hight, "Undrained anisotropy and principal stress rotation in saturated sand," Geotechnique, vol. 34, no. 1, pp. 11-27, 1984.

[5] K. Miura, S. Miura, and S. Toki, "Deformation behavior of anisotropic dense sand under principal stress axes rotation," Soils and Foundations, vol. 26, no. 1, pp. 36-52, 1986.

[6] Y. Nakata, M. Hyodo, H. Murata, and N. Yasufuku, "Flow deformation of sands subjected to principal stress rotation," Soils and Foundations, vol. 38, no. 2, pp. 115-128, 1998.

[7] Z.-X. Tong, J.-M. Zhang, Y.-L. Yu, and G. Zhang, "Drained deformation behavior of anisotropic sands during cyclic rotation of principal stress axes," Journal of Geotechnical and Geoenvironmental Engineering, vol. 136, no. 11, pp. 1509-1518, 2010.

[8] H. Akagi and J. Saitoh, "Dilatancy characeristics of clayey soil under principal axes rotation," in Proceedings of the International Symposium on Pre-Failure Deformation Characteristics of Geomaterial, Sapporo, Japan, 1994.

[9] P.-Y. Hicher and P. V. Lade, "Rotation of principal directions in $K_{0}$-consolidated clay," Journal of Geotechnical Engineering, vol. 113, no. 7, pp. 774-788, 1987.

[10] P. V. Lade and M. M. Kirkgard, "Effects of stress rotation and changes of 6-values on cross-anisotropic behavior of natural, $K_{0}$-consolidated soft clay," Soils and Foundations, vol. 40, no. 6 , pp. 93-105, 2000.

[11] H. Lin and D. Penumadu, "Experimental investigation on principal stress rotation in Kaolin clay," Journal of Geotechnical and Geoenvironmental Engineering, vol. 131, no. 5, pp. 633-642, 2005.

[12] A. Prashant and D. Penumadu, "Effect of intermediate principal stress on overconsolidated Kaolin Clay," Journal of Geotechnical and Geoenvironmental Engineering, vol. 130, no. 3, pp. 284-292, 2004.

[13] W.-K. Lam and F. Tatsuoka, "Effects of initial anisotropic fabric and $\sigma 2$ on strength and deformation characteristics of sand," Soils and Foundations, vol. 28, no. 1, pp. 89-106, 1988.

[14] A. Sayão and Y. P. Vaid, "Effect of intermediate principal stress on the deformation response of sand," Canadian Geotechnical Journal, vol. 33, no. 5, pp. 822-828, 1996.

[15] M. Yoshimine, K. Ishihara, and W. Vargas, "Effects of principal stress direction and intermediate principal stress on undrained shear behavior of sand," Soils and Foundations, vol. 38, no. 3, pp. 179-188, 1998.

[16] M. Kumruzzaman and J.-H. Yin, "Influences of principal stress direction and intermediate principal stress on the stressstrain-strength behaviour of completely decomposed granite," Canadian Geotechnical Journal, vol. 47, no. 2, pp. 164-179, 2010.

[17] S. Shibuya, D. W. Hight, and M. J. Symes, "Discussion on "Sand response to cyclic rotation of principal stress directions as induced by wave loads" by Ishihara and Towhata (1983)," Soils and Foundations, vol. 24, no. 3, pp. 107-110, 1984.

[18] Y. Shen, Experimental study on effect of variation of principal stress orientation on undisturbed soft clay [Ph.D. thesis], Zhejiang University, 2007, (Chinese).

[19] D. W. Hight, A. Gens, and M. J. Symes, "The development of a new hollow cylinder apparatus for investigating the effects of principal stress rotation in soils," Geotechnique, vol. 33, no. 4, pp. 355-383, 1983.

[20] H. B. Zheng, Experimental study of reconstituted clay and intact clay under principal stress rotation [M.S. thesis], Zhejiang University, 2012, (Chinese).

[21] J. Zhou and C. J. Xu, "Impact of shear stress on strain and pore water pressure behavior of intact soft clay under principal stressrotation," Geotechnical Testing Journal. Accepted.

[22] R. J. Jardine, "The effect on anisotropy of rotating the principal stress axes during consolidation," Geotechnique, vol. 51, no. 1, pp. 69-83, 2001.

[23] M. Gutierrez and K. Ishihara, "Non-coaxiality and energy dissipation in granular materials," Soils and Foundations, vol. 40, no. 2, pp. 49-59, 2000.

[24] Y. Y. Cai, An experimental study of non-coaxial soil behaviour using hollow cylinder testing [Ph.D. thesis], University of Nottingham, Nottingham, UK, 2010.

[25] Y. Y. Cai, H. S. Yu, D. Wanatowski, and X. Li, "Noncoaxial behavior of sand under various stress paths," Journal of Geotechnical and Geoenvironmental Engineering, vol. 139, no. 8, pp. 15091518, 2013.

[26] D. Pradel, K. Ishihara, and M. Gutierrez, "Yielding and flow of sand under principal stress axes rotation," Soils and Foundations, vol. 30, no. 1, pp. 87-99, 1990.

[27] H. Ohkawa, J. Kuwano, T. Nakada, and S. Tachibana, "Yielding characteristic and non-coaxiality of Toyoura sand on $p^{\prime}$ constant shear stress plane," Soils and Foundations, vol. 51, no. 1, pp. 179-190, 2011. 


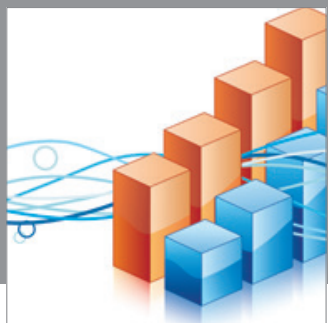

Advances in

Operations Research

mansans

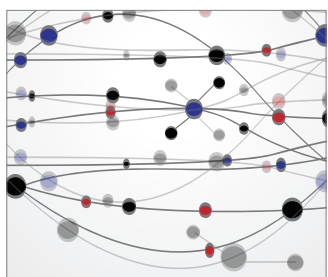

The Scientific World Journal
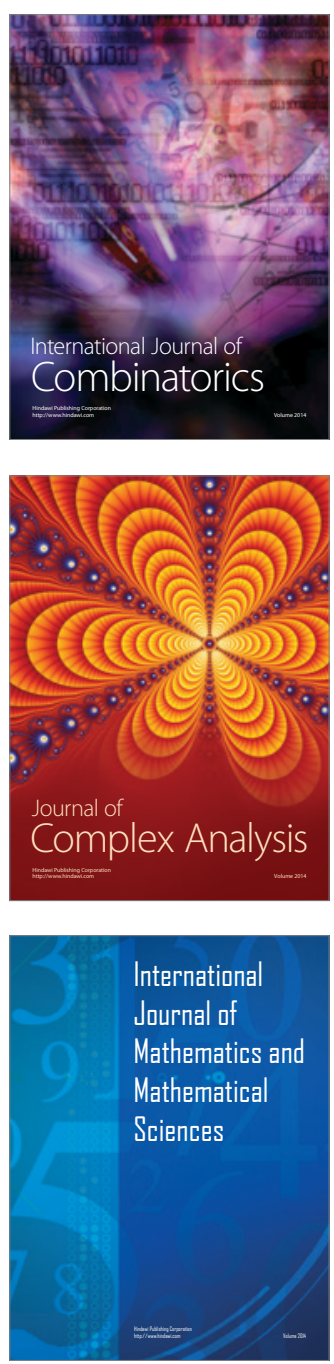
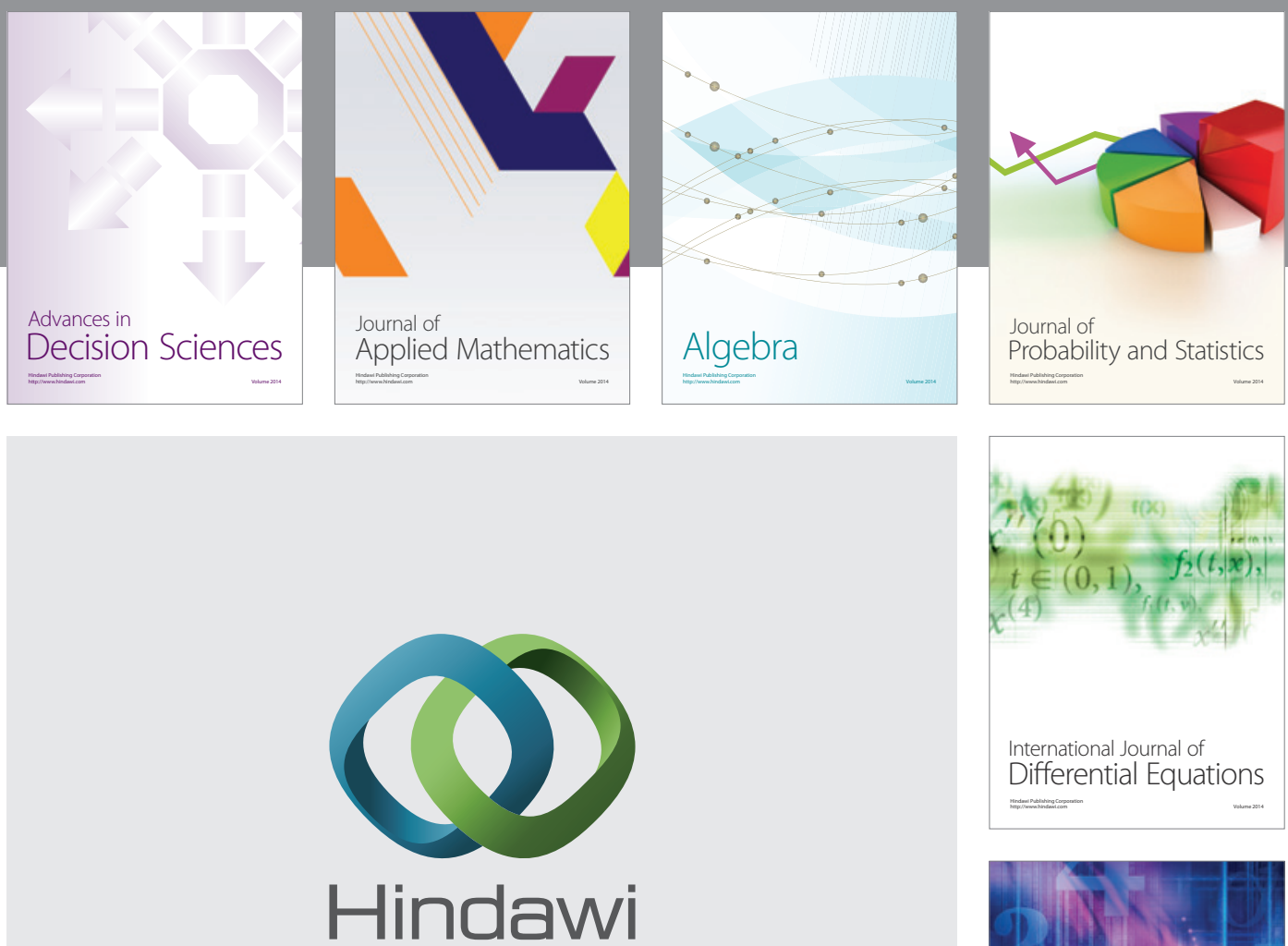

Submit your manuscripts at http://www.hindawi.com
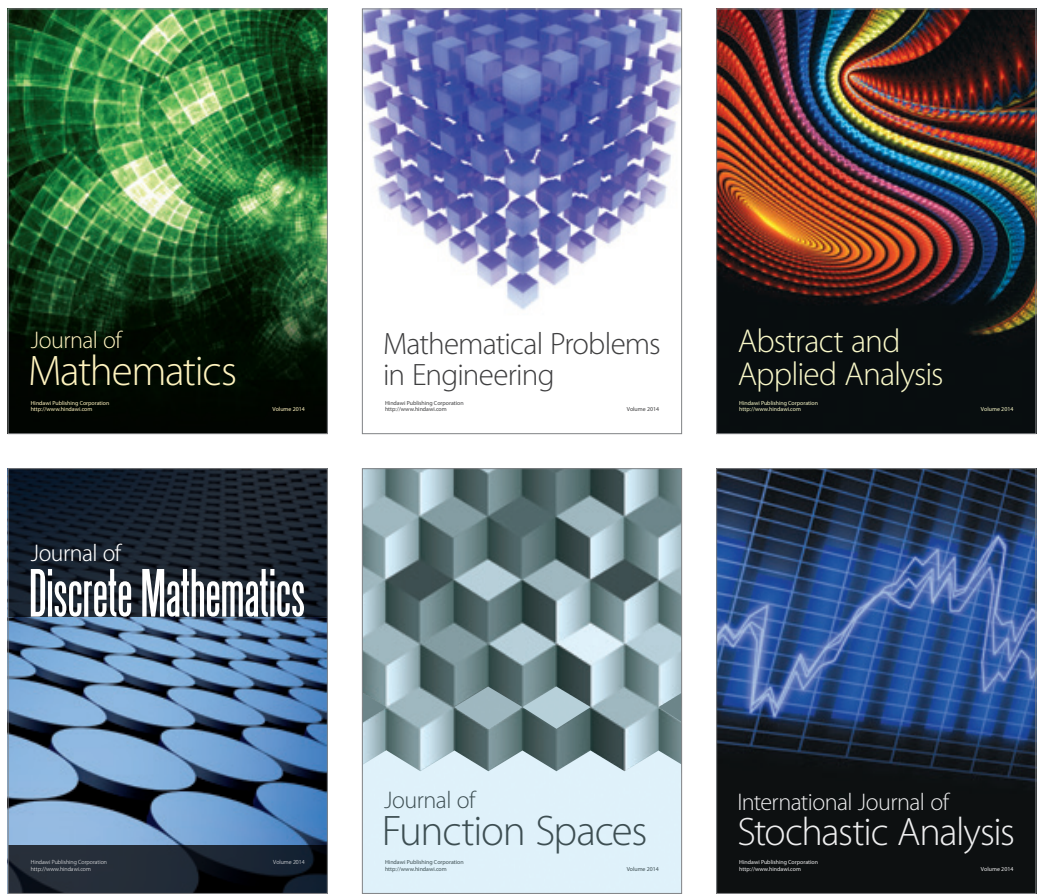

Journal of

Function Spaces

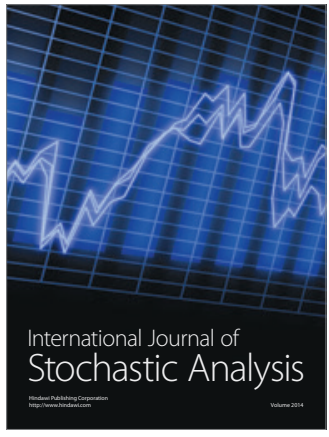

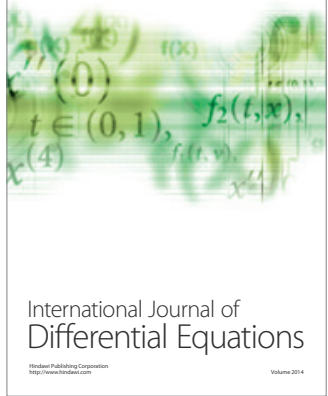
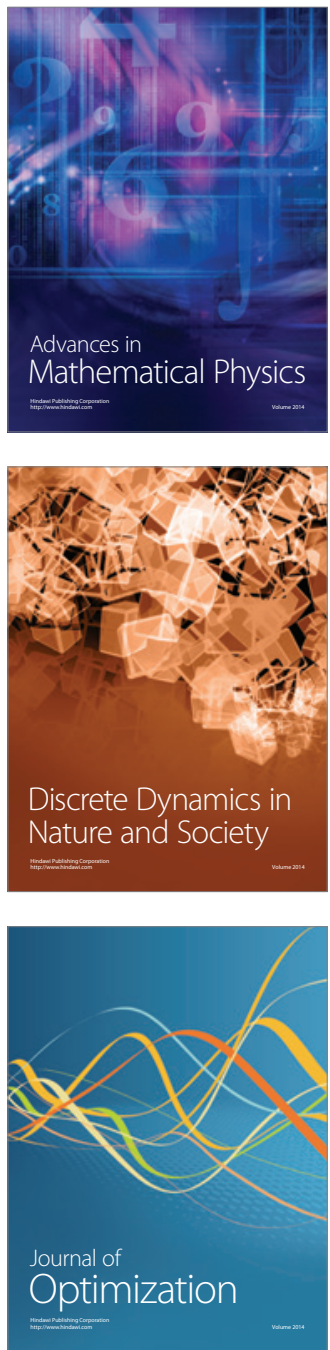